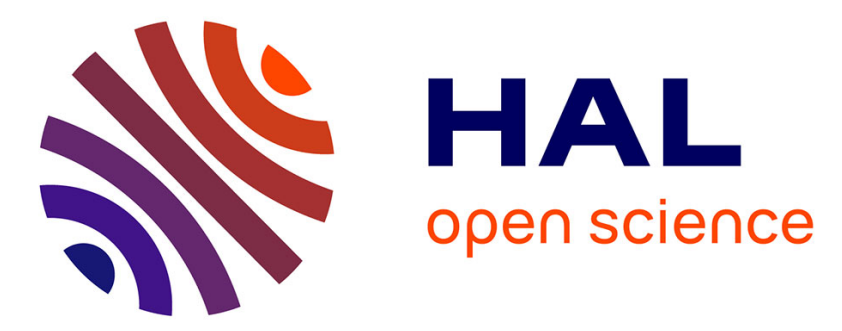

\title{
A Model of Evolution of a Collaborative Business Ecosystem Influenced by Performance Indicators
}

\author{
Paula Graça, Luis M. Camarinha-Matos
}

\section{To cite this version:}

Paula Graça, Luis M. Camarinha-Matos. A Model of Evolution of a Collaborative Business Ecosystem Influenced by Performance Indicators. 20th Working Conference on Virtual Enterprises (PRO-VE), Sep 2019, Turin, Italy. pp.245-258, 10.1007/978-3-030-28464-0_22 . hal-02478740

\author{
HAL Id: hal-02478740 \\ https://hal.inria.fr/hal-02478740
}

Submitted on 14 Feb 2020

HAL is a multi-disciplinary open access archive for the deposit and dissemination of scientific research documents, whether they are published or not. The documents may come from teaching and research institutions in France or abroad, or from public or private research centers.
L'archive ouverte pluridisciplinaire HAL, est destinée au dépôt et à la diffusion de documents scientifiques de niveau recherche, publiés ou non, émanant des établissements d'enseignement et de recherche français ou étrangers, des laboratoires publics ou privés. 


\title{
A Model of Evolution of a Collaborative Business Ecosystem Influenced by Performance Indicators
}

\author{
Paula Graça $\mathrm{a}^{\mathrm{a}, \mathrm{b}}$ and Luis M. Camarinha-Matos ${ }^{\mathrm{a}}$ \\ ${ }^{a}$ Faculty of Sciences and Technology and Uninova CTS, \\ NOVA University of Lisbon, Campus de Caparica, 2829-516 Caparica, Portugal \\ b Instituto Superior de Engenharia de Lisboa, Instituto Politécnico de Lisboa, \\ Rua Conselheiro Emídio Navarro 1, 1959-007 Lisbon, Portugal \\ mgraca@deetc.isel.pt, cam@uninova.pt
}

\begin{abstract}
The materialization of the $4^{\text {th }}$ Industrial Revolution needs to emphasize the role of collaboration. Traditional business ecosystems have evolved to hyperconnected organizations facing more advanced collaboration models, dynamic networks, and more complex smart systems. Emerging collaborative aspects in this context need to be identified, and tools developed to help organizations coping with changing environment, market, and societal needs. As such, an assessment model is proposed to measure the expected self-adjustment of organizations in a collaborative business ecosystem, induced by performance indicators, in order to improve the organizations themselves and the ecosystem as a whole. Organizations with distinct profiles, categorized by classes of responsiveness, respond differently to the collaboration opportunities they may receive, or are more likely to invite others to collaborate. This behaviour is expected to be influenced by the variation in importance (weight) of each specific performance indicator adopted in a given business ecosystem, as the organizations, like individuals, tend to evolve according to how they are evaluated. To assess the proposed approach, an experiment has been set up using a simulation model based on system dynamics and agents. Preliminary results, based on a number of relevant scenarios, are presented and discussed.
\end{abstract}

Keywords: Collaborative Networks, Business Ecosystem, Performance Indicators, System Dynamics, Agent Based Modelling.

\section{Introduction}

Business ecosystems are continuously evolving, accompanying the growing use of digital and collaborative platforms. Nowadays, they are shifting towards the age of Industry 4.0, more specifically to the notion of Collaborative Industry 4.0 [1]. The expression Business Ecosystem was first introduced by Moore and inspired by ecological ecosystems [2]. On the other hand, a business ecosystem it is also considered in the research area of Collaborative Networks $(\mathrm{CN})$ [3], which has a wider scope. As such and aiming to emphasize the collaboration dimension, the term Collaborative Business Ecosystem (CBE) has been introduced in [4] and a model proposed [5]. 
The aim of the present work is to assess the influence of performance indicators in a CBE, expecting to improve its behaviour and that of its individual organizations. There are several mechanisms to evaluate organizations individually, of which the balanced score cards (BSCs) [6] are the best-known. However, to evaluate collaboration benefits, only limited contributions can be found in the literature. As an example, [7] proposes a conceptual model for value systems in $\mathrm{CNs}$, and suggests a method for assessing the alignment of the value systems of their members [8]. Other examples in the field of supply chain collaboration (SCC), a relatively new research area that is growing fast [9], identify collaboration to improve performance in traditional SCs and propose a wide variety of methods and metrics in [10], [11] and [12]. Finally, the social network analysis (SNA) proposes a set of metrics related to the structure of the network, namely in [13] and [14], consisting of the most adequate approach as a contribution to the establishment of the performance indicators of the CBE.

For the evaluation of the $\mathrm{CBE}$ in this work, two of the performance indicators proposed in [5] and [15] (CI - Contribution Indicator and PI - Prestige Indicator) are detailed, as well as a proposal for an influence mechanism. For experimental assessment, the CBE is simulated by a Performance Assessment and Adjustment Model (PAAM) as proposed in [5], using agent based modelling (ABM) and system dynamics (SD) [16].

The remaining sections of this paper are organized as follows: section two describes the proposed simulation model, presenting its collaborative and assessment environment; section three shows how to calculate two of the performance indicators used to illustrate the assessment; section four presents the experimental evaluation of the model using a parametrized scenario to assess and verify the influence of indicators in its evolution, including a discussion of results. The last section summarizes the results and identifies the ongoing research and future work.

\section{A Simulation Model of a CBE}

The PAAM model illustrated in Figure 1, simulates a CBE environment populated by organizations (the agents) of different profiles, classified according to classes of responsiveness described in Table 1, thus allowing the establishment of diversified behaviors. To better respond to market opportunities, it is assumed that organizations collaborate by creating collaboration opportunities (CoOps) that they send and receive from each other. These collaborations generate "links" between organizations, weighted by the number of times they collaborate (\#CoOps). The higher values of \#CoOps mean stronger collaboration. 


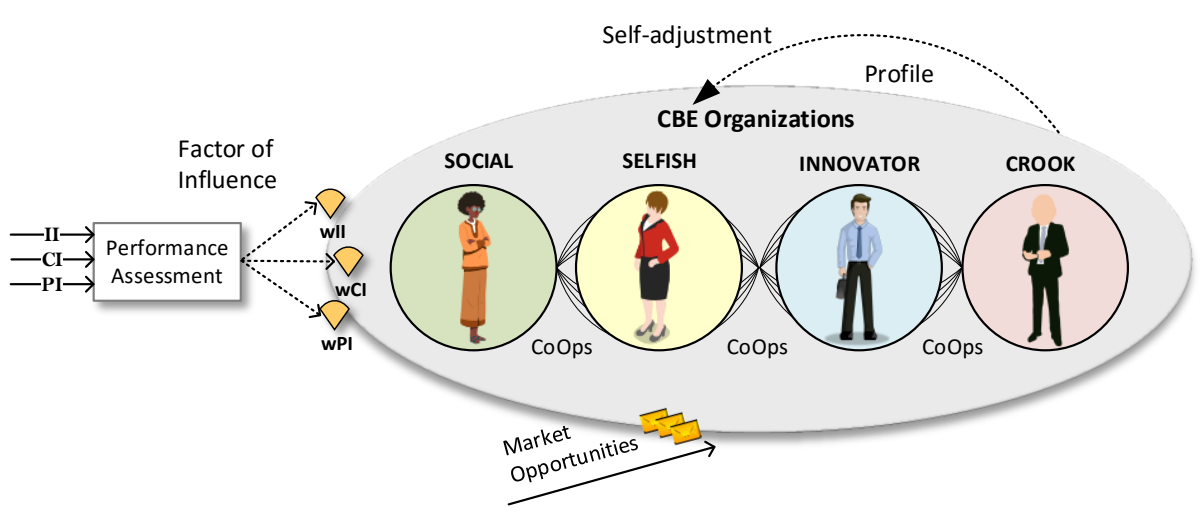

Figure 1. PAAM (Performance Assessment and Adjustment Model) for a CBE.

For a certain CBE, a variable number of organizations of each class of responsiveness can be used among those considered in Table 1: Social, Selfish, Innovator, and Crook, to better reproduce diversity in a true CBE. Each class is composed of three parameters to characterize the agents, whose values presented in Table 1 are merely illustrative and can be adjusted for each simulation scenario. These parameters (decimal values ranging from 0 to 1 ), are used as the probability of successful attempts in the distribution functions adopted by the model to simulate the random behaviour of the agents.

Table 1. Description of the classes of responsiveness of organizations.

\begin{tabular}{llcccc}
\hline \multicolumn{6}{c}{ Classes of Responsiveness of Organizations } \\
\hline & Parameters [0..1] & Social & Selfish & Innovator & Crook \\
\hline Contact rate & $\begin{array}{l}\text { Willingness to invite others to } \\
\text { collaborate }\end{array}$ & 0,8 & 0,1 & 0,4 & 0,3 \\
Accept rate & $\begin{array}{l}\text { Readiness to accept invitations } \\
\text { New products rate }\end{array}$ & 0,7 & 0,2 & 0,5 & 0,3 \\
& $\begin{array}{l}\text { Tendency to accept opportunities } \\
\text { related to innovation }\end{array}$ & 0,2 & 0,2 & 0,9 & 0,3 \\
\hline
\end{tabular}

\subsection{Collaborative Environment}

When an organization wants to collaborate with other organizations in the CBE, it requests so by sending a CoOp (taskDescription, resourcesToAssign), describing the task and specifying the amount of resources assigned. This amount is given by a binomial distribution as illustrated in formula (1), to get a value bounded between [0, resourcesToAssign] with a probability equal to the contactRate parameter. The higher the parameter, the more likely it is to get more resources to distribute. Organizations belonging to the Social class have the highest contactRate and those of the Selfish class the lowest. 


$$
\operatorname{contact}_{\text {to }} \text { collaborate }=\operatorname{binomial}(\text { contactRate, resourcesToAssign })
$$

On the other hand, the organizations that receive the invitations, if having available resources, accept with a probability given by the Bernoulli distribution [17] as illustrated in formula (2). The result is "yes/no" with the "yes" having a probability equal to the acceptRate parameter. The higher the parameter, the more likely the collaboration is to be accepted. Organizations belonging to the Social class also have the highest acceptRate and those of the Selfish class the lowest.

$$
\text { accept }_{\text {collaboration }}=\text { bernoulli }(\text { acceptRate }) \& \& \text { resourcesAvailable }
$$

Finally, if the CoOp refers to a task related to innovation, which may result in the development of new products or patents, then the organizations also accept the collaboration according to the Bernoulli distribution as illustrated in formula (3), but with a probability equal to the newProductsRate parameter. The higher the parameter, the more likely the collaboration is to be accepted. Organizations belonging to the Innovators class have the highest newProductRate and those of the Social and the Selfish class the lowest.

$$
\text { accept } t_{\text {collaboration }}=\text { bernoulli }(\text { newProductsRate }) \& \& \text { resourcesAvailable }
$$

\subsection{Assessment Environment}

A performance assessment mechanism can be used to assess the CBE and its individual organizations, based on the indicators proposed in [5] and [15]: the Innovation Indicator (II), to evaluate the proficiency of the organizations to create new products or patents; the Contribution Indicator (CI), to evaluate the value generated by the collaboration; and the Prestige Indicator (PI), to evaluate the prominence of a particular organization over others, to participate in collaboration.

The weight (significance) given to each performance indicator by the CBE manager, is expected to act as a factor of influence, resulting in a certain achievement of organizations, which as individuals, tend to adjust according to the way they are evaluated. For demonstrative purposes, a scenario of simulation was created with three main components of common business activity: research and development (R\&D), Consulting, and Inner tasks. For the realization of each component, the organizations allocate a given percentage of resources according to their class of responsiveness. Table 2 illustrates a sample of a possible allocation used in the current experiment (the Crook class was not considered). 
Table 2. Sample of resources allocation by business activity and class of responsiveness.

\begin{tabular}{lcccc}
\hline \multicolumn{5}{c}{ Resources Allocation } \\
\hline \multicolumn{1}{c}{ Activity } & Social & Selfish & Innovator & Crook \\
\hline R\&D & $10 \%$ & $10 \%$ & $30 \%$ & N/A \\
Consulting & $70 \%$ & $60 \%$ & $60 \%$ & N/A \\
Inner tasks & $20 \%$ & $30 \%$ & $10 \%$ & N/A \\
\hline
\end{tabular}

It is assumed that the variation in the weights of the performance indicators by the CBE manager, will act as a factor of influence over the organizations, causing their self-adjustment trying to improve their profile, resulting in an improvement of the CBE as a whole. Therefore, as illustrated in Figure 2, it is considered that an influence mechanism acts on the percentage of resources allocated to each business activity, called respectively slice for $R \& D$, slice for Consulting and slice for InnerTasks. The factor of influence (FI) of the mechanism, is expressed as a percentage (for instance $10 \%$ ) of improvement to be distributed among the slices according to the weights of the performance indicators ( $w I I, w C I$ and $w P I)$, causing a reallocation of resources and a consequent self-adjustment of the organizations' behaviour. It is also assumed that the resources for $\mathrm{R} \& \mathrm{D}$ are influenced by the weight $w I I$, and the resources for consulting, are influenced by the weights $w C I$ and $w P I$.

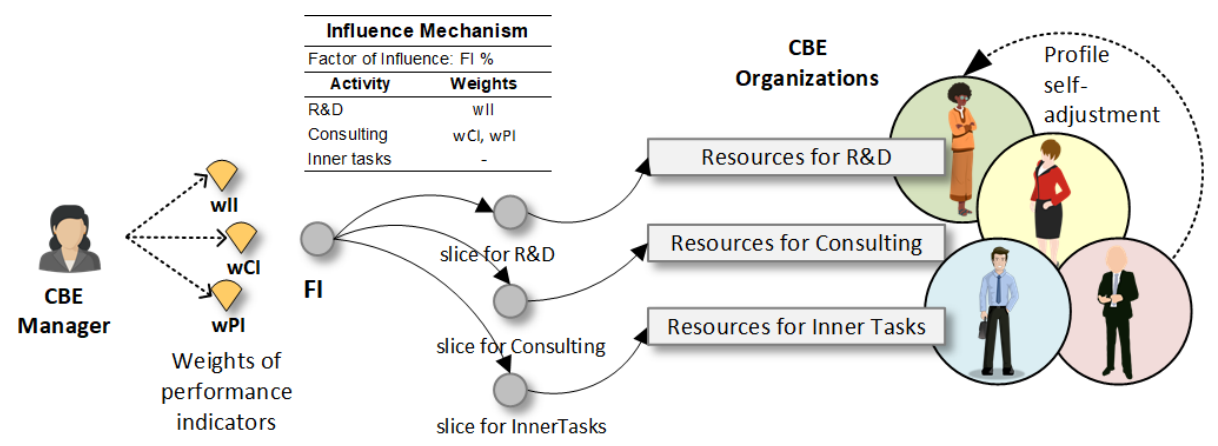

Figure 2. Detail of the influence mechanism used for the presented simulation model.

Considering the resources allocation of Table 2 as a base distribution, the influence mechanism can be expressed by formulas (4), (5) and (6).

$$
\begin{aligned}
& \text { slice }_{\text {for } R \& D}=\text { slice }_{\text {for } R \& D_{\text {base }}}-\frac{F I}{3}+\frac{w I I * F I}{w I I+w C I+w P I} \\
& \text { slice }_{\text {forConsulting }}=\text { slice }_{\text {forConsulting }_{\text {base }}}-\frac{F I}{3}+\frac{(w C I+w P I) * F I}{w I I+w C I+w P I}
\end{aligned}
$$




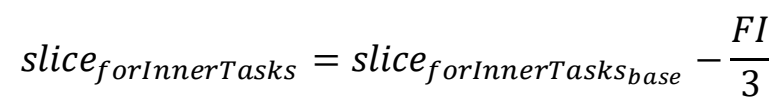

According to these formulas, the influence mechanism subtracts the FI equally from the three slices of resources, so that it can be redistributed by considering the weights of the indicators.

\section{Performance Indicators to Assess the Influence on the CBE}

Two of the performance indicators proposed in [5], are used in this work to assess the $\mathrm{CBE}$ and the influence on the behaviour of its organizations in terms of collaboration. The Contribution Indicator (CI), to measure the total value created by collaboration in the $\mathrm{CBE}$ as a whole and that of its individual organizations, and the Prestige Indicator (PI), to measure the influence/prominence of the organizations in the CBE.

Table 3 and Table 4 describe the metrics used to calculate the performance indicators $\mathrm{CI}$ and PI, of the organizations' collaboration and that of the CBE as a whole.

Table 3. Metrics of the Contribution Indicator.

\begin{tabular}{|c|c|}
\hline \multicolumn{2}{|r|}{ Metrics of the Contribution Indicator (CI) } \\
\hline Metric & Description \\
\hline $\mathrm{O}_{1, \cdots, \mathrm{O}_{\mathrm{n}}}$ & Organizations in the $\mathrm{CBE}$ \\
\hline \#O & Number of organizations in the $\mathrm{CBE}$ \\
\hline$\# \mathrm{CoOp} \mathrm{p}_{\mathrm{i}}$ in & No. of collaboration opportunities the organization $\mathrm{O}_{\mathrm{i}}$ gained from the $\mathrm{CBE}$ \\
\hline$\# \mathrm{CoOp}_{\mathrm{i}}$ out & No. of collaboration opportunities the organization $\mathrm{O}_{\mathrm{i}}$ brought in the $\mathrm{CBE}$ \\
\hline$\sum_{\mathrm{i}} \# \mathrm{CoOp} \mathrm{p}_{\mathrm{i}}$ & Total no. of collaboration opportunities created in the CBE \\
\hline $\mathrm{C}_{\mathrm{D}}\left(\mathrm{O}_{\mathrm{i}}\right)$ in/out & Weighted indegree/outdegree centrality $\left(\mathrm{C}_{\mathrm{D}}\right)$ of the organization $\mathrm{O}_{\mathrm{i}}$ in the \\
\hline & $\begin{array}{l}\text { CBE, which stands for the sum of direct connections in/out of } \mathrm{O}_{\mathrm{i}} \text { to the } \mathrm{n} \\
\text { organizations } \mathrm{O}_{\mathrm{j}} \text {, with weight } \# \mathrm{CoOp}_{\mathrm{ij}}\end{array}$ \\
\hline $\mathrm{C}_{\mathrm{D}}\left(\mathrm{O}^{*}\right)$ in/out & Maximum indegree/outdegree centrality of $\mathrm{O}_{\mathrm{i}}$ \\
\hline
\end{tabular}

The $C_{i}$ in of an organization, assesses the contribution of the organization $O_{i}$ in terms of accepted collaboration opportunities. The value $C I_{i}$ in is thus obtained by the weighted degree centrality of $O_{i}$ calculated by formula (7), which is more related to the popularity of organizations [18].

$$
C I_{i} \text { in }=\frac{C_{D}\left(O_{i}\right) \text { in }}{C_{D}\left(O^{*}\right) \text { in }}=\frac{\sum_{j} O_{i j} \# C o O p_{i j} \text { in }}{\max \sum_{j} O_{i j} \# C o O p_{i j} \text { in }}
$$

The $C I_{i}$ out of an organization, assesses the contribution of the organization $O_{i}$ in terms of created collaboration opportunities. The value $C I_{i}$ out is thus obtained by the weighted outdegree centrality of $O_{i}$ calculated by formula (8), which is more related to the activity of organizations [18]. These values are normalized between 0 and 1 in relation to the maximum degree centrality for the current network. 


$$
C I_{i} \text { out }=\frac{C_{D}\left(O_{i}\right) \text { out }}{C_{D}\left(O^{*}\right) \text { out }}=\frac{\sum_{j} O_{i j} \# C o O p_{i j} \text { out }}{\max \sum_{j} O_{i j} \# C o O p_{i j} \text { out }}
$$

The $C I_{C B E}$ in and the $C I_{C B E}$ out of the $\mathrm{CBE}$, assess respectively the degree to which the most popular organization in terms of accepted collaboration opportunities and the most active organization in terms of created collaboration opportunities, exceeds the contribution of the others. The values $C I_{C B E}$ in and $C I_{C B E}$ out are thus obtained by the weighted degree centrality of the CBE as a whole calculated by formulas (9) and (10), i.e. the sum of differences between the contribution of the most popular/active organization $\left(O^{*}\right)$ and that of all organizations in the CBE. These values are normalized between 0 and 1 in relation to the maximum possible sum of differences of degree centralities for the current network.

$$
\begin{array}{r}
C I_{C B E} \text { in }=\frac{C_{D}(C B E) \text { in }}{\max C_{D}(C B E) \text { in }}=\frac{\sum_{i}\left[C_{D}\left(O^{*}\right) \text { in }-C_{D}\left(O_{i}\right) \text { in }\right]}{C_{D}\left(O^{*}\right) \text { in } *(\# O-1)} \\
C I_{C B E} \text { out }=\frac{C_{D}(C B E) \text { out }}{\max C_{D}(C B E) \text { out }}=\frac{\sum_{i}\left[C_{D}\left(O^{*}\right) \text { out }-C_{D}\left(O_{i}\right) \text { out }\right]}{C_{D}\left(O^{*}\right) \text { out } *(\# O-1)}
\end{array}
$$

The $C I_{C B E} t$, calculated by formula (11), is a ratio of the total number of collaboration opportunities created in the CBE by the total number of organizations.

$$
C I_{C B E} t=\frac{\sum_{i} \# C o O p_{i}}{\# O}
$$

\begin{tabular}{|c|c|}
\hline \multicolumn{2}{|r|}{ Metrics of the Prestige Indicator (PI) } \\
\hline Metric & Description \\
\hline $\mathrm{O}_{1, \ldots, \mathrm{O}_{\mathrm{n}}}$ & Organizations in the CBE \\
\hline \#O & Number of organizations in the CBE \\
\hline$\# \mathrm{CoOp}_{\mathrm{i}}$ in & $\begin{array}{l}\text { No. of income collaboration opportunities the organization } \mathrm{O}_{i} \text { participated in } \\
\text { the } \mathrm{CBE}\end{array}$ \\
\hline$\# \mathrm{CoOp}_{\mathrm{i}}$ out & $\begin{array}{l}\text { No. of outcome collaboration opportunities the organization } \mathrm{O}_{\mathrm{i}} \text { participated } \\
\text { in the } \mathrm{CBE}\end{array}$ \\
\hline$\# \mathrm{CoOp} \mathrm{p}_{\mathrm{kj}}$ in/out & $\begin{array}{l}\text { No. of income/outcome collaboration opportunities between the } \\
\text { organization } \mathrm{O}_{\mathrm{k}} \text { and } \mathrm{O}_{\mathrm{j}} \text { in the } \mathrm{CBE}\end{array}$ \\
\hline $\mathrm{C}_{\mathrm{B}}\left(\mathrm{O}_{\mathrm{i}}\right)$ in/out & Weighted income/outcome betweenness centrality $\left(\mathrm{C}_{\mathrm{B}}\right)$ of the organization \\
\hline & $\begin{array}{l}\mathrm{O}_{i} \text { in the } \mathrm{CBE} \text {, which stands for the sum of overall partial betweenness of } \mathrm{O}_{\mathrm{i}} \\
\text { relative to all pairs } \mathrm{O}_{\mathrm{kj}} \text {, assuming that connections between } \mathrm{O}_{\mathrm{k}} \text { and } \mathrm{O}_{\mathrm{j}} \text { have } \\
\text { weight of } \# \mathrm{CoOp} \mathrm{p}_{\mathrm{kj}}\end{array}$ \\
\hline $\mathrm{C}_{\mathrm{B}}\left(\mathrm{O}^{*}\right)$ in/out & Maximum income/outcome betweenness centrality of $\mathrm{O}_{\mathrm{i}}$ \\
\hline
\end{tabular}

Table 4. Metrics of the Prestige Indicator. 
The $P I_{i}$ in of an organization, assesses the prominence of the organization $O_{i}$ in terms of accepted collaboration opportunities. It means the extent to which a node (organization) is part of transactions (collaboration) among other nodes [18]. Using Freeman's betweenness measure [13], this means the number of times that an organization is on the shortest paths among all pairs of the other organizations. In a binary network, the shortest path means the smallest number of intermediate nodes between two organizations. However, in weighted networks, the transactions (collaboration) between two nodes (organizations) might be faster (more expressive) with more intermediate nodes that are strongly connected [18]. This is due to the fact that stronger intermediate nodes mean more collaboration between organizations. The value $P I_{i}$ in is thus obtained by the weighted betweenness centrality calculated by formula (12), which stands for the sum of overall partial betweenness of $O_{i}$ relative to all pairs $O_{k j}$ assuming that connections between any $O_{k}$ organization and any other $O_{j}$ have weight of $\# C o O p_{k j}$ in.

$$
P I_{i} \text { in }=\frac{C_{B}\left(O_{i}\right) \text { in }}{C_{B}\left(O^{*}\right) i n}=\frac{\sum_{k} \sum_{j} O_{k j}\left(O_{i}\right) \text { in }}{\max \sum_{k} \sum_{j} O_{k j}\left(O_{i}\right) \text { in }}
$$

The $P I_{i}$ out of an organization, assesses the prominence of the organization $O_{i}$ in terms of created collaboration opportunities. Similarly to $P I_{i}$ in, $P I_{i}$ out is calculated by formula (13). These values are normalized between 0 and 1 in relation to the maximum betweenness centrality for the current network.

$$
P I_{i} \text { out }=\frac{C_{B}\left(O_{i}\right) \text { out }}{C_{B}\left(O^{*}\right) \text { out }}=\frac{\sum_{k} \sum_{j} O_{k j}\left(O_{i}\right) \text { out }}{\max \sum_{k} \sum_{j} O_{k j}\left(O_{i}\right) \text { out }}
$$

The $P I_{C B E}$ in and $P I_{C B E}$ out of the CBE, assess respectively the degree to which the most prominent organization in terms of accepted collaboration opportunities and the most prominent organization in terms of created collaboration opportunities, exceeds the contribution of the others. The values $P I_{C B E}$ in and $P I_{C B E}$ out are thus obtained by the weighted betweenness centrality of the $\mathrm{CBE}$ as a whole calculated by formulas (14) and (15), i.e. the average of the differences between the preponderance of the most influent organization $\left(O^{*}\right)$ and that of all organizations in the CBE. These values are normalized between 0 and 1 in relation to the maximum possible sum of differences of betweenness centralities for the current network.

$$
\begin{gathered}
P I_{C B E} \text { in }=\frac{C_{B}(C B E) \text { in }}{\max C_{B}(C B E) \text { in }}=\frac{\sum_{i}\left[C_{B}\left(O^{*}\right) \text { in }-C_{B}\left(O_{i}\right) \text { in }\right]}{C_{B}\left(O^{*}\right) \text { in } *(\# O-1)} \\
P I_{C B E} \text { out }=\frac{C_{B}(C B E) \text { out }}{\max C_{B}(C B E) \text { out }}=\frac{\sum_{i}\left[C_{B}\left(O^{*}\right) \text { out }-C_{B}\left(O_{i}\right) \text { out }\right]}{C_{B}\left(O^{*}\right) \text { out } *(\# O-1)}
\end{gathered}
$$


The PI indicator, as shown in formulas (12), (13), (14) and (15), uses the betweenness centrality to evaluate the preponderance of organizations' collaboration in the CBE. For this, the Floyd-Warshall algorithm [19] was applied to find the shortest paths in the weighted graph represented by the CBE and its organizations connected by collaboration opportunities. The algorithm starts with a distance matrix $D$ with $n$ lines and $n$ columns, where $n$ is the number of nodes $(\# O)$ and each position of the matrix $D[i, j]$ contains the weight (\#CoO $p_{i j}$ ) between the node $i\left(O_{i}\right)$ and node $j\left(O_{j}\right)$. Because the shortest paths in the $\mathrm{CBE}$ mean stronger connections between the organizations, i.e. more collaboration, the inverse of the $\# C o O p_{i j}$ is used, resulting in the matrix (16).

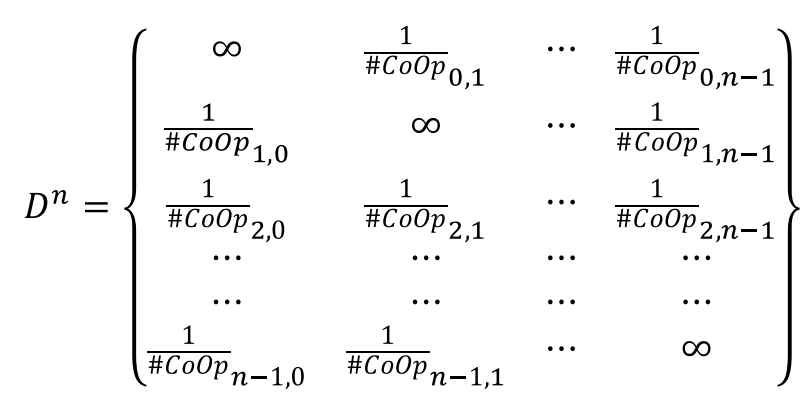

The shortest paths matrix is then obtained after $k=0 . . n-1$ iterations over the $D^{n}$ distance matrix, where in each $k$ iteration, the $D^{k}$ matrix is calculated according to formula (17).

$$
D_{i j}^{n}=\min \left(D_{i j}^{n-1}, D_{i k}^{n-1}+D_{k j}^{n-1}\right)
$$

Finally, to compute the betweenness centrality of each node, i.e. the number of times that an organization $O_{i}$ is on the shortest paths among all pairs of the other organizations $O_{k j}$, the Floyd-Warshall algorithm [19] had to be improved. A path matrix $P$ was used to register the shortest paths between all pairs, starting with the matrix $P^{0}$ calculated according to (18).

$$
P_{i j}^{0}=\left\{\begin{array}{c}
\text { null if } i=j \text { or } D_{i j}=\infty \\
i \text { in all other cases }
\end{array}\right.
$$

The final $P^{n}$ matrix is reached after $k=0 . . n-1$ iterations, where in each $k$ iteration, the $P^{k}$ matrix is calculated according to formula (19).

$$
P_{i j}^{n}=\left\{\begin{array}{c}
P_{i j}^{n-1} \text { if } D_{i j}^{n-1}<D_{i k}^{n-1}+D_{k j}^{n-1} \\
P_{i j}^{n-1} \cup P_{k j}^{n-1} \text { if } D_{i j}^{n-1}=D_{i k}^{n-1}+D_{k j}^{n-1} \\
P_{k j}^{n-1} \text { if } D_{i j}^{n-1} D_{i k}^{n-1}+D_{k j}^{n-1}
\end{array}\right.
$$


All the metrics and formulas described in this chapter, were used to calculate the performance indicators in the experimental evaluation of the CBE.

\section{Experimental Evaluation of the CBE}

To build the proposed PAAM described in chapter 2, for the experimental evaluation of the $\mathrm{CBE}$, and to implement the performance indicators described in chapter 3, the AnyLogic Multimethod Simulation Software [16] was used. The model depicted in Figure 3, simulates an environment (the CBE), populated by agents (the organizations), whose behaviour is represented by state-charts and system dynamics, to represent stocks and flows of resources.

The income market opportunities (incomingMarketOps) are also modelled by agents arriving at a rate of $1.000 /$ year plus a $25 \%$ of opportunities for new products or patents, following the Poisson distribution (adequate for modelling the number of times an event occurs in an interval of time) [20]. Each incomingMarketOps is composed of a task description (research or consulting) and a number of resources (days-man) estimated to perform the task (generated by a uniform distribution bounded by [1..50 days-man]).

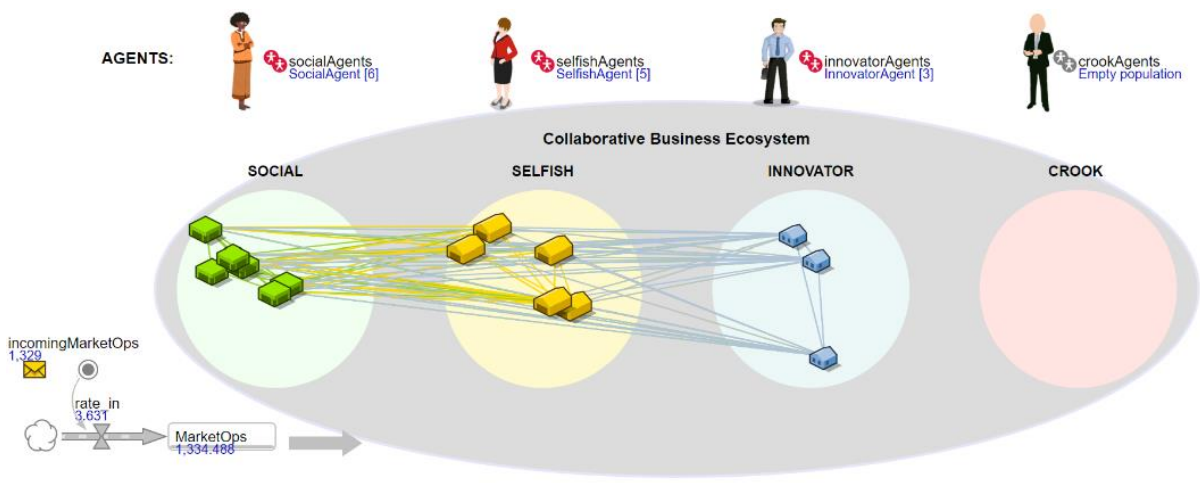

Figure 3. PAAM model after an iteration of one year.

The organizations, whose profile is differentiated by classes of responsiveness, respond to incomeMarketOps interacting by sending and receiving collaboration opportunities $(\mathrm{CoOps})$. To fulfil the tasks, the available resources are consumed according to the type of business activity ( $R \& D$, Consulting or Inner tasks) and the amount of estimated resources. The influence mechanism of the Figure 2 induces a reallocation of resources causing a self-adjustment in the profile of the organizations.

For the present experimental evaluation, the PAAM simulation model was parametrized to represent a CBE composed of 6 Social organizations, 5 Selfish and 3 Innovative. The organizations were configured with the values described in Table 1 and Table 2, having an initial amount of resources of 1.500/year (day-man).

Running the model considering the interval of one year, the performance indicators $\mathrm{CI}$ and PI were calculated, resulting in the values displayed in Table 5. Columns $C I_{i}$ in 
and $\mathrm{CI}_{i}$ out show respectively the contribution of the organization $O_{i}$ in terms of accepted CoOps, and the contribution in terms of created CoOps by inviting other organizations to collaborate. On the other hand, columns $P I_{i}$ in and $P I_{i}$ out show respectively the prominence of the organization $O_{i}$, i.e. the extent to which $O_{i}$ is part of the collaboration among the other organizations in terms of accepted or invited CoOps. Finally, the performance indicators related to the whole CBE, have the following results: $C I_{C B E} t=26,4$ is the ratio of the total number of $C o O p s$ generated in the CBE by the total number of organizations; $C I_{C B E}$ in $=0,444$ and $C I_{C B E}$ out $=0,214$, are respectively the degree to which the most popular organization (\#CoOps received) and the most active (\#CoOps created), exceeds the contribution of the others; $P I_{C B E}$ in $=$ 0,776 and $P I_{C B E}$ out $=0,686$, are respectively the degree to which the most prominent organization (being part of the CoOps received or created ) exceeds the contribution of the others.

Table 5. Values of the CI and PI for each individual organization and for the CBE.

\begin{tabular}{c|c|c|c|c}
\hline \multicolumn{3}{c}{ Contribution and Prestige Indicators (Cl and PI) } \\
\hline Class of Resp. & $\mathbf{C l}_{\mathbf{i}}$ in & $\mathbf{C l}_{\mathbf{i}}$ out & $\mathbf{P I}_{\mathbf{i}}$ in & $\mathbf{P I}_{\mathbf{i}}$ out \\
\hline \multirow{4}{*}{ Social } & 0,89 & 0,97 & 1,00 & 0,83 \\
& 0,58 & 1,00 & 0,44 & 0,63 \\
& 0,64 & 0,76 & 0,17 & 0,12 \\
& 0,76 & 0,64 & 0,17 & 0,33 \\
& 0,82 & 0,82 & 0,68 & 0,97 \\
& 0,71 & 0,70 & 0,16 & 0,21 \\
\hline \multirow{5}{*}{ Selfish } & 0,20 & 0,58 & 0,00 & 0,00 \\
& 0,27 & 0,85 & 0,00 & 0,00 \\
& 0,20 & 0,94 & 0,33 & 0,33 \\
& 0,20 & 0,73 & 0,00 & 0,00 \\
& 0,22 & 0,79 & 0,00 & 0,00 \\
\hline \multirow{5}{*}{ Innovator } & 0,76 & 0,85 & 0,71 & 1,00 \\
& 1,00 & 0,94 & 0,54 & 0,96 \\
& 0,98 & 0,67 & 0,01 & 0,01 \\
\hline \multirow{5}{*}{} & $\mathrm{Cl}_{\mathrm{CBE}} \mathbf{t}$ & $\mathbf{2 6 , 4}$ & & \\
& $\mathrm{Cl}_{\mathrm{CBE}}$ in & $\mathbf{0 , 4 4 4}$ & $\mathbf{P I}_{\mathrm{CBE}}$ in & $\mathbf{0 , 7 7 6}$ \\
& $\mathrm{Cl}_{\mathrm{CBE}}$ out & $\mathbf{0 , 2 1 4}$ & $\mathbf{P I}_{\mathrm{CBE}}$ out & $\mathbf{0 , 6 8 6}$ \\
\hline
\end{tabular}

The indicators $C I_{C B E}$ in/out reveal a better distribution of the collaboration than the $P I_{C B E}$ in/out, since these values are normalized between 0 and 1 , with zero indicating an equal distribution of collaboration among all organizations.

Running the model again for a period of one year and parameterizing the influence mechanism as shown in Table 6 , the results of Table 7 were achieved. 
Table 6. Parametrization of the influence mechanism.

\begin{tabular}{c|ccc}
\hline \multicolumn{4}{c}{ Influence Mechanism } \\
\hline Factor of Influence & \multicolumn{3}{c}{ Weights } \\
\hline $\mathrm{FI}$ & $\mathrm{wll}$ & $\mathrm{wCl}$ & $\mathrm{wPI}$ \\
$10 \%$ & 1 & 4 & 2 \\
\hline
\end{tabular}

Comparing the results of Table 5 and Table 7, it can be observed that the more significant difference in the CBE after applying the influence mechanism, is that all the organizations tried to be more active creating more CoOps. The indicator $C_{C B E} t$ increased from 26,4 to 26,7 (showing a higher average of collaboration opportunities by organization, although not very significant), and the $C I_{i}$ out (invites to collaborate sent by organization) also increased for almost all the organizations, flattening $C I_{C B E}$ out from 0,214 to 0,178 (showing a more uniform collaboration among organizations) at the same time. On the other hand, the $P I_{i}$ in also had an increase (more prestige concerning invitations received) but only in the Social and Innovator classes, resulting in a better $P I_{C B E}$ in from 0,776 to 0,742 (showing a more uniformization of the prestige among organization), but still showing a high polarized distribution. Finally, no further significant differences were registered.

Table 7. Values of the CI and PI for each individual organization and for the CBE, after the influence mechanism.

\begin{tabular}{|c|c|c|c|c|}
\hline \multicolumn{5}{|c|}{ Contribution and Prestige Indicators ( $\mathrm{Cl}$ and $\mathrm{PI})$} \\
\hline Class of Resp. & $\mathrm{Cl}_{\mathrm{i}}$ in & $\mathrm{Cl}_{\mathrm{i}}$ out & $\mathrm{PI}_{\mathrm{i}}$ in & $\mathrm{PI}_{\mathrm{i}}$ out \\
\hline \multirow{6}{*}{ Social } & 0,85 & 1,00 & 1,00 & 0,77 \\
\hline & 0,55 & 1,00 & 0,45 & 0,57 \\
\hline & 0,62 & 0,81 & 0,22 & 0,15 \\
\hline & 0,72 & 0,66 & 0,22 & 0,36 \\
\hline & 0,79 & 0,88 & 0,76 & 0,99 \\
\hline & 0,66 & 0,78 & 0,18 & 0,21 \\
\hline \multirow{5}{*}{ Selfish } & 0,21 & 0,56 & 0,00 & 0,00 \\
\hline & 0,26 & 0,91 & 0,00 & 0,00 \\
\hline & 0,21 & 0,97 & 0,33 & 0,33 \\
\hline & 0,17 & 0,78 & 0,00 & 0,00 \\
\hline & 0,23 & 0,81 & 0,00 & 0,00 \\
\hline \multirow{3}{*}{ Innovator } & 0,72 & 0,88 & 0,79 & 1,00 \\
\hline & 1,00 & 0,97 & 0,71 & 0,98 \\
\hline & 0,96 & 0,69 & 0,15 & 0,02 \\
\hline \multicolumn{2}{|r|}{$\mathrm{Cl}_{\mathrm{CBE}} \mathrm{t}$} & 26,7 & & \\
\hline \multicolumn{2}{|r|}{$\mathrm{Cl}_{\mathrm{CBE}}$ in } & 0,465 & $\mathrm{PI}_{\mathrm{CBE}}$ in & 0,742 \\
\hline \multicolumn{2}{|r|}{$\mathrm{Cl}_{\mathrm{CBE}}$ out } & 0,178 & $\mathrm{PI}_{\mathrm{CBE}}$ out & 0,687 \\
\hline
\end{tabular}

Although the previous observed responses of a CBE and its individual organizations, to the proposed influence mechanism are not very significant so far, these are preliminary results using arbitrary parameters so that the modelling and simulation concept can be illustrated. Other improvements to the influence mechanism should be 
made as well as the adjustment of the parameters used in order to obtain more meaningful conclusions.

\section{Conclusions and Further Work}

The PAAM model and the experimental evaluation in the previous section showed that a CBE can be evaluated through performance indicators, more specifically, the proposed CI and PI. It also showed that a CBE can evolve by self-adjusting of the behaviour of its organizations, when influenced by the variation of the weights (significance) of the adopted performance indicators.

The ongoing work is related to the improvement of the influence mechanism, enhancing the calculation formulas by introducing more variables in addition to the allocated resources.

Future work includes the calculation of the Innovation Indicator (II), correlating it with collaboration. On the other hand, the PAAM model should be more dynamic, basing the decision to collaborate not on distribution functions, but depending on the performance of organizations. Finally, more refined and tested simulation scenarios should be carried out using all classes of responsiveness with different and dynamic parametrizations.

Acknowledgments. This work benefited from the ongoing research within the CoDIS (Collaborative Networks and Distributed Industrial Systems Group) which is part of both the New University of Lisbon (UNL) - Faculty of Sciences and Technology, and the UNINOVA - CTS (Center of Technology and Systems). Partial support also comes from Fundação para a Ciência e Tecnologia through the PEST program UID/EEA/00066/2019.

\section{References}

1. Luis M. Camarinha-Matos, Rosanna Fornasiero, and Hamideh Afsarmanesh. Collaborative networks as a core enabler of industry 4.0. In Collaboration in a Data-Rich World, IFIP AICT 506, pages 3-17. Springer International Publishing, 2017.

2. James F Moore. Predators and prey: a new ecology of competition. Harvard business review, 71(3):75-86, 1993.

3. Luis M Camarinha-Matos and Hamideh Afsarmanesh. Collaborative networks: a new scientific discipline. Journal of intelligent manufacturing, 16(4-5):439-452, 2005.

4. Paula Graça and Luis M. Camarinha-Matos. The need of performance indicators for collaborative business ecosystems. In Technological Innovation for Cloud-Based Engineering Systems, pages 22-30. Springer International Publishing, 2015.

5. Paula Graça and Luis M. Camarinha-Matos. Evolution of a collaborative business ecosystem in response to performance indicators. In Collaboration in a Data-Rich World, IFIP AICT 506, pages 629-640. Springer International Publishing, 2017.

6. Robert S Kaplan and David P Norton. The balanced scorecard: translating strategy into action. Harvard Business Press, 1996. 
7. Luis M. Camarinha-Matos and Patrícia Macedo. A conceptual model of value systems in collaborative networks. Journal of Intelligent Manufacturing, 21(3):287-299, Jun 2010.

8. Patricia Macedo and Luis M. Camarinha-Matos. A qualitative approach to assess the alignment of value systems in collaborative enterprises networks. Computers \& Industrial Engineering, 64(1):412 - 424, 2013.

9. Usha Ramanathan. Performance of supply chain collaboration â€“ a simulation study. Expert Systems with Applications, 41(1):210 - 220, 2014.

10. Ann Vereecke and Steve Muylle. Performance improvement through supply chain collaboration in europe. International journal of operations \& production management, 26(11):1176-1198, 2006.

11. H Lorentz, Y Shi, O-P Hilmola, JS Srai, Usha Ramanathan, Angappa Gunasekaran, and Nachiappan Subramanian. Supply chain collaboration performance metrics: a conceptual framework. Benchmarking: An international journal, 18(6):856-872, 2011.

12. Usha Ramanathan and Angappa Gunasekaran. Supply chain collaboration: Impact of success in long-term partnerships. International Journal of Production Economics, 147:252-259, 2014.

13. Linton C Freeman. Centrality in social networks conceptual clarification. Social networks, 1(3):215-239, 1978.

14. Matthew O Jackson. Social and economic networks, volume 3. Princeton university press Princeton, 2008.

15. Paula Graça and Luís M. Camarinha-Matos. A proposal of performance indicators for collaborative business ecosystems. In Collaboration in a Hyperconnected World, pages 253-264. Springer International Publishing, 2016.

16. A. Borshchev. The Big Book of Simulation Modeling: Multimethod Modeling with AnyLogic 6. AnyLogic North America, 2013.

17. J. H. C. W. Introduction to mathematical probability. Science Progress (1933- ), 33(130):350-350, 1938.

18. Tore Opsahl, Filip Agneessens, and John Skvoretz. Node centrality in weighted networks: Generalizing degree and shortest paths. Social networks, 32(3):245-251, 2010.

19. Robert W. Floyd. Algorithm 97: Shortest path. Commun. ACM, 5(6):345-, June 1962.

20. Frank A Haight and Frank A Haight. Handbook of the poisson distribution. 1967. New York: Jon Wiley \& Sons, 1967. 